\title{
Journal of Bacteriology and

\section{Genotypic Characteristics of Outpatient Antibiotic Resistance and Nosocomial Staphylococcus aureus Strains}

\author{
YA Tyurin ${ }^{1,2^{*}}$, LT Bayazitova ${ }^{2}$, TA Chazova ${ }^{2}$, ID Reshetnikova ${ }^{2,3}$ and Tyurina $\mathrm{NY}^{4}$ \\ ${ }^{1}$ Kazan State Medical University, Butlerova Street 49, Kazan 420012, Russia \\ ${ }^{2}$ Kazan Scientific-Research Institute of Epidemiology and Microbiology, Bolchaya Krasnaya Street 67, Kazan, 420015, Russia \\ ${ }^{3}$ Kazan Federal University, Kremlin Street 18, Kazan, 420008, Russia \\ ${ }^{4}$ OOO (Stomatologic Clinic No9 of Kazan), Kazan, Chistopolsky Street 43, 420124, Russia
}

"Corresponding author: Yury A Tyurin, Head of Scientific Research laboratory of immunology and allergens development, Kazan Scientific Research Institute of Epidemiology and Microbiology of Rospotrebnadzor, Kazan State Medical University, Republic of Tatarstan, Butlerova Street 49, Kazan 420012, Russia, Tel: 8(843)236 67 91; E-mail: tyurin.yurii@yandex.ru

Received date: September 07, 2017; Accepted date: November 08, 2017; Published date: November 13, 2017

Copyright: (2017 Tyurin YA, et al. This is an open-access article distributed under the terms of the creative commons attribution license, which permits unrestricted use, distribution, and reproduction in any medium, provided the original author and source are credited.

\begin{abstract}
The article presents the results of a study of antibiotic resistance of 191 methicillin-sensitive (MSSA) and methicillin-resistant (MRSA) strains Staphylococcus aureus (S. aureus), isolated from outpatient and hospital patients. The data of molecular-genetic typing of strains of $S$. aureus and established types of SCCmec cassettes. There were significant differences in the sample genotype MRSA strains isolated from patients and hospital outpatient profile. Isolates from outpatients, contained in its composition genetic elements SCCmec IV a, c, d types. MRSA, isolates from hospital patients profile were identified only type II SCCmec cassettes. Vancomycin, fusidic acid, mupirocin antistaphylococcal possessed high activity against MRSA and MSSA. MRSA were more resistant to antimicrobial drugs compared to MSSA. Azithromycin and clindamycin demonstrated moderate anti-staphylococcal activity. Revealed low activity of chloramphenicol, tetracycline and erythromycin against staphylococci strains.
\end{abstract}

Keywords: Methicillin-sensitive; Methicillin-resistant; Staphylococcus aureus, Genotyping SCCmec; Health-care associated MRSA; Communiti-acquired MRSA

\section{Introduction}

The incidence of health-related infections (hepat-care associated infections) remains high. In addition to socially-mediated factors associated with the sanitary and epidemiological situation, "socially independent" factors play a role, such as the selection of highly virulent strains of microorganisms with multiple resistance to antimicrobial agents-antibiotics, antiseptics, disinfectants [1,2]. In the etiological structure of ISMP, Staphylococcus aureus remains relevant. In the epidemiological aspect, methicillin (oxacillin) resistant staphylococci are significant; first of all, Staphylococcus aureus (Meticillin resistant Staphylococcus aureus-MRSA) [3]. There are nosocomial and out-ofhospital strains of MRSA. Strains acquired as a result of hospitalization or associated with the provision of medical care are recorded as HAMRSA-(healt-care associated MRSA). Patients who do not seek medical care in recent months are characterized by "out-of-hospital" strains of MRSA-(communiti-acquired MRSA, CA-MRSA) [4]. Strains CA-MRSA and HA-MRSA differ in phenotypic and genotypic characteristics. Methicillin resistance of staphylococci depends on the presence of the mec complex in the chromosomal cassette (SCCmec). The main elements of this complex are: $\operatorname{mec} A$, a structural gene encoding the production of an additional penicillin-binding protein (PSB-2a); mecI and mecR1 are the components responsible for the transcription of mecA4, mec-associated DNA [5].

The genetic characteristic of all MRSA, regardless of the genotypes of the SCCmec element, is the presence of the mecA gene that causes the resistance of these strains to oxacillin and beta-lactam antibiotics and ccr-complex genes that encode proteins that excose and site specific integration of mecA into the staphylococcus genome [6]. Mobile genetic elements SCCmec which include cassettes IV and V types can be transferred from some $S$. aureus strains to others fairly freely, in comparison with SCCmec cassettes of I, II and III types, usually not having mobility [7]. It should be noted that strains containing SCCmec IV-V types in their genome, due to pronounced mobility and ability to horizontal transfer, pose a major epidemiological hazard in the spread of MRSA and the transmission of this trait between staphylococci colonizing the human body. Mobile genetic elements of SCCmec I, II and III types are usually present in hospital clones of methicillin-resistant staphylococci (HA-MRSA), characterized by the presence of antibiotic resistance genes for other groups (tobramycin, kanamycin, tetracycline, erythromycin) [8]

Currently, molecular genetic methods have established that there is a fairly clear relationship between the MRSA membership of a certain genetic "background" and the content of a certain type of SCCmec in DNA [9]. Strains containing SCCmec type IV are among the most numerous clonal group of CC8. This group includes such epidemic related strains and clones as EMRSA-2, $-6,-12,-13,-14$ prevalent in the UK, USA, Germany, France and the Netherlands [10]. It should be noted that SCCmec type IV is often detected in epidermal staphylococci ( $S$. epidermidis), which are representatives of the normobiocenosis of the skin and mucous membranes, and is supposed to transfer this mobile element from staphylococcus $S$. epidermidis to coagulase-positive $S$. aureus within one biotope of the human body [11].

The aim of the study was to study the profile of antibiotic resistance and molecular-genetic typing of Staphylococcus aureus for the 
Citation: Tyurin YA, Bayazitova LT, Chazova TA, Reshetnikova ID, Tyurina NY (2017) Genotypic Characteristics of Outpatient Antibiotic Resistance and Nosocomial Staphylococcus aureus Strains. J Bacteriol Parasitol 8: 328. doi:10.4172/2155-9597.1000328

Page 2 of 4

presence of SCCmec complexes isolated in patients treated in outpatient and inpatient settings.

\section{Materials and Methods}

\section{Objects of research}

The study included 191 clinical strains of $S$. aureus, isolated in 2007-2014 from outpatient patients examined in the outpatient clinic of Kazan Scientific Research Institute of Epidemiology and Microbiology of Rospotrebnadzor and patients ("out-patients") receiving hospital treatment ("hospital") in Kazan. MRSA strains isolated from outpatients are sown from the nasal mucosa and nasal passages in patients with upper respiratory tract infections and from areas of affected skin in patients with atopic dermatitis. Hospital strains of MRSA are sown from wound detachable skin in patients with burn injuries; from the nasal cavity in patients with purulent rhinosinusitis, from the oral mucosa in patients with aphthous stomatitis, pericoranoritis, paradontal abscess.

\section{Bacteriological methods}

Cultivation of strains of $S$. aureus was carried out on $5 \%$ blood agar, mannitol-salt yolk agar (Columbia, Conda, Spain). Identification of $S$. aureus was carried out according to morphological features, biochemical methods in accordance with normative documents. The profile of sensitivity to antimicrobial agents was determined by the disc-diffusion method using the Müller-Hinton medium according to MUK 4.2.1890-04 "Determination of the sensitivity of microorganisms to antibacterial drugs". Screening of methicillin resistance in $S$. aureus was performed using a disk with nitrocellin and then plated onto the chromogenic MRSA Agar chromomer Agar Biomerioux. Interpretation of antibiotic sensitivity data was carried out in accordance with NCSLS 2008 standards.

\section{Molecular-genetic methods}

Genotyping of $S$. aureus was carried out according to the protocol presented in the guidelines of the Federal Center for Hygiene and Epidemiology of Rospotrebnadzor, 2006 [12]. Extraction of genomic DNA from the strains was carried out according to the protocols of commercial ZR Genomic DNA II KitTM kits. Identification of SCCme types was carried out by PCR amplification using 12 pairs of primers (oligonucleotides) synthesized in company "Sintol", Moscow, Russia. At the first stage, the specificity of the set of genes coding for the synthesis of recombinases (type ccr $1,2,3.5$ ) was determined. Then, the set of genes belonging to the mec complex (class A or class B, using the primers MecI and IS272) was determined (Table 2). The amplification results with the determination of these sets of genes allowed identification of the presence of SCCmec I, II and III types. Identification of the presence of SCCmec IV a, b, c, d primers IS272, as well as T-IVa-T-IVd were used; in addition, primers TV and ccr-type 5 were used in the detection of SCCmec V type (Table 1).

\begin{tabular}{|c|c|c|c|}
\hline Name primers & $\begin{array}{l}\text { Type of identifiable } \\
\text { SCCmec }\end{array}$ & Nucleotide sequence (5'-3') & $\begin{array}{l}\text { Size of amplicon } \\
\text { (bp) }\end{array}$ \\
\hline T-IVa & ScCmeclVa & GCCTTATTCGAAGAAACCG CTACTCTTCTGAAAAGCGTCG & 776 \\
\hline $\mathrm{T}-\mathrm{IVb}$ & SCCmeclVb & TCTGGAATTACTTCAGCTGC AAACAATATTGCTCTCCCTC & 493 \\
\hline T-IVc & SCCmeclVc & ACAATATTTGTATTATCGGAGAGC TTGGTATGAGGTATTGCTGG & 200 \\
\hline T-IVd & SCCmeclVd & CTCAAAATACGGACCCCAATACA TGCTCCAGTAATTGCTAAAG & 880 \\
\hline$T-V$ & SCCmecV & GAACATTGTTACTTAAATGAGCG TGAAAGTTGTACCCTTGACACC & 330 \\
\hline MecA147 & Ген тесА & GTGAAGATATACCAAGTGATT ATGCGCTATAGATTGAAAGGAT & 150 \\
\hline ccr-type 1 & SCCmec I & ATTGCCTTGATAATAGCCTCT AACCTATATCATCAATCAGTACGT & 700 \\
\hline ccr-type 2 & ScCmec II & ATTGCCTTGATAATAGCCTCT TAAAGGCATCAATGCACAAACACT & 1000 \\
\hline ccr-type 3 & SCCmec III & ATTGCCTTGATAATAGCCTCT AGCTCAAAAGCAAGCAATAGAAT & 1600 \\
\hline Mecl & Класс А mec & CAAGTGATTTGAAACCGCCT CAAAAGGACTGGACTGGAGTCCAAA & 180 \\
\hline IS272 & Класс В mес & ACCGCCACTCATAACATAAGGAA TATACCAACCCGACAAC & 2000 \\
\hline ccr-type 5 & SCCmecV & ATG-AAT TCAAAGAGGATGGC GATTTAGAATTGTCGTGATTGC & 336 \\
\hline
\end{tabular}

Table 1: Primers used to identify SCCmec types.

PCR was carried out using the standard composition of the reaction mixture, the volume of one sample was $20 \mu \mathrm{l}$. Primers were introduced at a final concentration of $300 \mathrm{nmol}$, the concentration of the DNA template to $10 \mathrm{ng}$. Detection of primer-specific amplicons was carried out in a $2 \%$ agarose gel by horizontal electrophoresis using intercalating ethidium bromide dye and markers (Fermentas, DNA Ladder). Visualization of the results was carried out by the transluminator (Vilber Lourmat, SCX-15 M, France).
The reference strains were used: for intralaboratory quality control of antibiotic resistance-Staphylococcus aureus ATCC 25923 (State Collection of Pathogenic Microorganisms, Moscow); for control of molecular-genetic typing SCCmec-cassettes isolated DNA from Staphylococcus aureus M307, Staphylococcus aureus M 258, Staphylococcus aureus 252, Staphylococcus aureus 720, Staphylococcus aureus E84/5528/1, Staphylococcus aureus I-78. (State Collection of Pathogenic Microorganisms, Moscow). 
Citation: Tyurin YA, Bayazitova LT, Chazova TA, Reshetnikova ID, Tyurina NY (2017) Genotypic Characteristics of Outpatient Antibiotic Resistance and Nosocomial Staphylococcus aureus Strains. J Bacteriol Parasitol 8: 328. doi:10.4172/2155-9597.1000328

Page 3 of 4

\section{Results}

From outpatient patients 166 strains of $S$. aureus were isolated. In this group, the occurrence of MRSA strains according to phenotypic identification was $27.1 \%$.

A characteristic feature of the strain isolated from this group of patients was the prevalence $(72.9 \%)$ of methicillin-sensitive strains (MSSA), compared with the group of hospital patients $(44.0 \%)$. In hospital patients strains of $S$. aureus $(\mathrm{n}=28)$ were characterized by a predominance $(56.0 \%)$ of methicillin-resistant isolates (MRSA).

It should be noted that some strains isolated from patients, both outpatient and hospital profile, were phenotypically moderately resistant to oxacillin, while molecular genetic analysis of DNA obtained from these strains revealed primer specific amplicons of the mecA gene in $30.1 \%$ of cases for outpatient and $64.0 \%$ for hospital isolates (Table 2).

\begin{tabular}{|l|l|l|l|}
\hline \multirow{2}{*}{ Patient groups } & \multicolumn{3}{|c|}{ Strains, n, } \\
\cline { 2 - 4 } & Phenotype & Genotype \\
\cline { 2 - 4 } & MRSA & MSSA & gene mecA $^{+}$ \\
\hline Outpatient profile patients $(n=56)$ & $45(27,1 \%)$ & $\begin{array}{l}121 \\
(72,9 \%)\end{array}$ & $49(30,1 \%)$ \\
\hline Total & \multicolumn{3}{|c|}{$166(100 \%)$} \\
\hline Hospital patients $(n=28)$ & $14(56,0 \%)$ & $\begin{array}{l}11 \\
(44,0 \%)\end{array}$ & $16(64,0 \%)$ \\
\hline Total & \multicolumn{3}{|c|}{$25(100 \%)$} \\
\hline
\end{tabular}

Table 2: The results of determining the sensitivity to oxacillin and the identification of the mecA gene in strains of $S$. aureus isolated from patients of two groups.

At the first stage of the study, the sensitivity of MRSA and MSSA strains to antimicrobial agents was determined.

The results of antibiotic susceptibility testing showed that glycopeptides (vancomycin) are highly active against $S$. aureus clinical isolates, all isolates were absolutely sensitive to this drug. The dominant numbers of strains were sensitive to fusidic acid: $98.02 \%$ MSSA $S$. aureus and $94.6 \%$ MRSA. A high anti-staphylococcal activity showed mupirocin (94.6\% of MRSA isolates and $100 \%$ of MSSA strains). Clindamycin proved to be a less effective antistaphylococcal drug (84.6\% for MSSA isolates and $75.7 \%$ for strains of MRSA); the proportion of gentamicin-sensitive isolates was $88.5 \%$ of MSSA and $70.27 \%$ of MRSA cultures. There was also a low activity of MRSA to erythromycin (54.1\%); to tetracycline $54.0 \%$ and to chloramphenicol $56.7 \%$ of sensitive crops. MSSA was more sensitive to these antimicrobial agents. Thus, $77.5 \%$ of the strains were sensitive to chloramphenicol, $76.9 \%$ to tetracycline and $71.2 \%$ to erythromycin. Macrolides remained active drugs against the dominant majority of MSSA ( $78.8 \%$ of azithromycin susceptible cultures); and MRSA in only $67.5 \%$ of cases are susceptible to azithromycin.

In second stage of the study, molecular-genetic typing of mecApositive DNA strains was carried out and the types of SCCmec cassettes were established. The genotype of all isolated MRSA strains from patients of the outpatient and hospital profile in a one-stage study showed significant typical differences (Figure 1). An analysis of the distribution of the types of SCCmec cassettes present in the genome of the investigated $S$. aureus strains showed (Figure 1) that strains isolated from outpatients, contained the genetic elements of SCCmec IV a, c, d types present in most isolates, the so-called community-acquired MRSA (CA-MRSA) [12]. In the MRSA strains isolated from patients in the hospital profile, only SCCmec cassettes of type II, as a rule, typical for hospital clones MRSA [12].

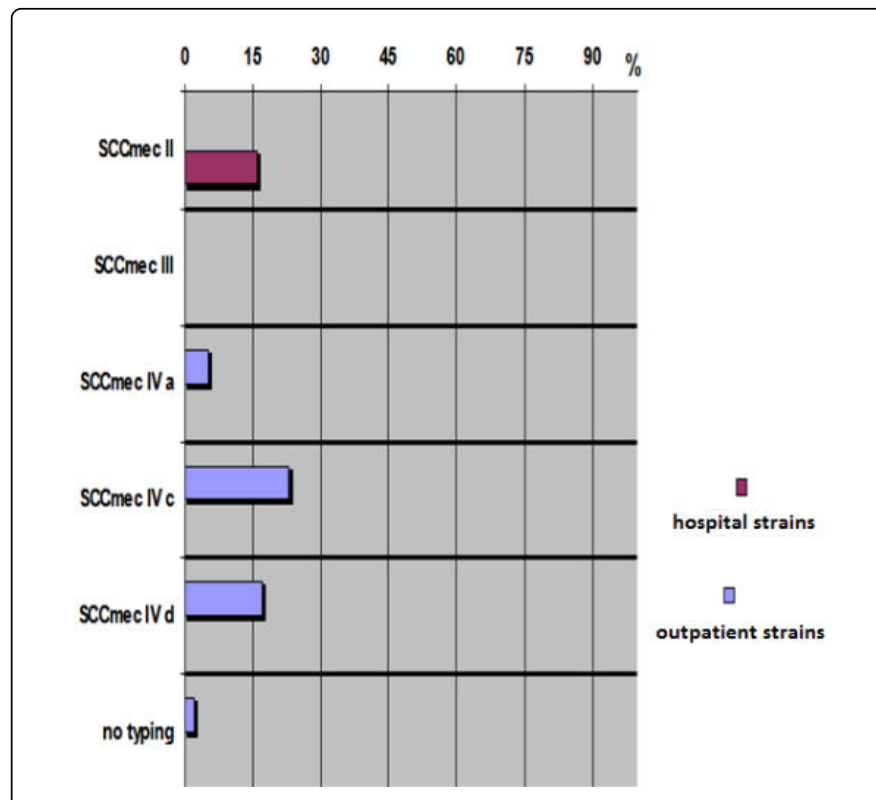

Figure 1: An analysis of the distribution of the types of SCCmec cassettes present in the genome of the investigated $S$. aureus strains.

\section{Conclusion}

The results of the study indicate that high antistaphylococcal activity against both MRSA and MSSA strains had vancomycin, fusidic acid and mupirocin. Methicillin-resistant isolates showed greater resistance to antimicrobial drugs than methicillin-sensitive cultures. Azithromycin and clindamycin have shown moderate antistaphylococcal activity. There was a low activity of chloramphenicol, tetracycline and erythromycin. Molecular-genetic typing of MRSA revealed significant differences in the structure of SCCmec cassettes. Isolates of methicillin-resistant strains of $S$. aureus isolated from patients of the hospital profile in its genome contained SCCmec of type II cassette, and strains from outpatients were type IV of SCCmec. There is a need to organize effective surveillance and control of the circulation of CA-MRSA and HA-MRSA strains in a particular region, especially at the local level-a medical and preventive institution, which will allow the development of measures to prevent the growth of multiple $S$. aureus resistance, conduct adequate antimicrobial therapy and sanitation-anti-epidemic measures.

\section{Conflicts of Interest}

The authors declare no conflicts of interest.

\section{References}

1. Semina HA, Kovaleva EP, Akimkin VG (2006) Osobennosti ehpidemiologii i ehpidemiologicheskogo nadzora za vnutribol'nichnymi 
Citation: Tyurin YA, Bayazitova LT, Chazova TA, Reshetnikova ID, Tyurina NY (2017) Genotypic Characteristics of Outpatient Antibiotic Resistance and Nosocomial Staphylococcus aureus Strains. J Bacteriol Parasitol 8: 328. doi:10.4172/2155-9597.1000328

Page 4 of 4

infektsiyami na sovremennom ehtape. Epidemiologiya i infektsionnye bolezni 4: 22-26.

2. Tutel'yan AV, Pisarev VM, Gaponov AM, Akimkin VG (2010) Perspektivy nauchnykh issledovanij $\mathrm{v}$ oblasti profilaktiki infektsij, svyazannykh s okazaniem meditsinskoj pomoshhi. EHpidemiologiya $\mathrm{i}$ infektsionnye bolezni 2: 10-12.

3. Chambers H (2001) The Changing epidemiology of Staphylococcus aureus? Emerg Inf Dis 7: 178-182.

4. Maltezou HC, Giamarellou H (2006) Community-acquired methicillinresistant Staphylococcus aureus infections. Int J Antimicrob Agents 27: 87-96.

5. Ito T, Kuwahara-Arai K, Katayama Y, Uehara Y, Han X, et al. (2007) Staphulococcal cassette chromosome mec ( $\mathrm{SScmec}$ ) analysis of MRSA Methods Mol Biol 391: 87-102.

6. Katayama Y, Ito T, Hiramatsu K (2000) A new class of genetic element staphylococcus cassette chromosome mec, encodes methicillin resistance in Staphylococcus aureus. Antimicrob Agents Chemother 44: 1549-1555.

7. Fey PD, Saïd-Salim B, Rupp ME, Hinrichs SH, Boxrud DJ, et al. (2003) Comparative molecular analysis of community- or hospital-acquired methicillin-resistant Staphylococcus aureus. Antimicrob Agents Chemother 47: 96-203.

8. Okuma K, Iwakawa K, Turnidge JD, Grubb WB, Bell JM, et al. (2002) Dissemination of new methicillin-resistant Staphylococcus aureus clones in the community. J Clin Microbiol 40: 4289-4294.

9. Robinson DA, Enright MC (2003) Evolutionary models of the emergence of methicillin-resistant Staphylococcus aureus. Antimicrob Agents Chemother 47: 3926-393410.

10. Wielders CL, Vriens MR, Brisse S, de Graaf-Miltenburg LA, Troelstra A, et al. (2001) In-vivo transfer of mecA DNA to Staphylococcus aureus. Lancet 357: 1674-1675.

11. Hiramatsu K, Longzhu C, Kuroda M, Ito T (2001) The emergence and evolution of methicillin-resistant Staphylococcus aureus. Trend Microbiol 9: 486-493.

12. Metitsillin rezistentnye Staphylococcus aureus (2006) vozbuditeli vnutribol'nichnykh infektsij: identifikatsiya i genotipirovanie. Metodicheskie rekomendatsii-M.: Federal'nyj tsentr gigieny i ehpidemiologii Rospotrebnadzora, Moskva. 